\title{
Analisis Kinerja Simpang Monumen Trunojoyo di Kecamatan Sampang, Kabupaten Sampang
}

\author{
Performance Analysis of the Trunojoyo Monument Intersection in \\ Sampang District
}

\author{
A. Yusuf Zuhdy ${ }^{1, a)}$, Triaswati M. Notodiningrat ${ }^{1, b)}$, Aan Fauzi ${ }^{1, c)} \&$ Lukman Yusuf $^{2, d)}$ \\ ${ }^{1)}$ Departemen Teknik Infratruktur Sipil, Institut Teknologi Sepuluh Nopember, Surabaya. \\ ${ }^{2)}$ Departemen Perencanaan Wilayah dan Kota, Institut Teknologi Sepuluh Nopember, Surabaya.
}

Koresponden : ${ }^{a)}$ yuf_di@yahoo.com

\begin{abstract}
ABSTRAK
Lokasi stategis Kabupaten Sampang yang berada pada jalur lintas pergerakan dari arah Timur-Barat Pulau Madura. Penduduk Kabupaten Pamekasan dan Kabupaten Sumenep yang menuju ke arah Surabaya atau sebaliknya, harus melintasi wilayah kabupaten Sampang. Kemacetan yang terjadi di Kecamatan Sampang bersifat lokal dan terjadi di beberapa simpang ketika jam sibuk. Simpang Monumen Trunojoyo termasuk Simpang yang menimbulkan kemacetan. Kemacetan di Simpang Monumen Trunojoyo di sebabkan oleh Simpang ini berada pada Jalur Jalan Nasional Surabaya-Sumenep yang di lewati kendaraat berat dan padat. Tujuan dari penelitian ini adalah untuk menilai kinerja Simpang Monumen Trunojoyo di Kecamatan Sampang. Hasil penelitiannya yaitu kinerja Simpang Monumen Trunojoto pada seluruh pendekat memiliki tingkat pelayanan di bawah standard yaitu $\leq 0.75$. Simulasi solver dilakukan untuk meningkatkan kinerja simpang dengan merubah siklus pada persinyalan, terutama memodifikasi waktu hijau (detik) serta memodifikasi lebar efektif setiap pendekat. Didapatkan hasil optimasi nilai DS berkisar antara 0.66 hingga $0.7<0.75$.
\end{abstract}

Kata Kunci : manajemen infrastruktur, pengopereasian infrastruktur jalan, analisis kinerja, jam sibuk, tingkat pelayanan, persinyalan.

\section{PENDAHULUAN}

Infrastruktur harus dikelola dengan baik. Begitu pula infrastruktur jalan, yang merupakan salah satu infrastruktur pokok bagi kehidupan wilayah, harus dioperasikan dan dipelihara dengan baik (Suprayitno \& Soemitro 2018). Bentuk pengoperasian infrastruktur jaringan jalan biasa dikenal sebagai Manajemen Lalu-Lintas dalam Ilmu Transportasi. Dengan demikian, Manajemen Lalu Lintas harus dilakukan dengan baik. Mengoperasikan ruas jalan dan persimpangan mempunyai kekhasan dan ukuran kinerja masing-masing (Halim, Mustari \& Zakariah 2019; Wibisono \& Cahyono 2018).

Seiring dengan pertumbuhan jumlah kendaraan yang sangat tinggi dan tidak seimbang dengan pertumbuhan prasarana jalan (pembangunan jalan baru ataupun pelebaran jalan eksisting) maka kepadatan lalu lintas akan semakin besar. Meningkatnya kepadatan lalu lintas mengakibatkan kelancaran pergerakan kendaran semakin berkurang (Rosadi, Abidin, \& Huda, 2018). Khususnya pada jam-jam sibuk yang biasanya terjadi pada pagi hari saat masyarakat memulai aktivitas rutinnya, dan sore hari saat masyarakat pulang dari tempat beraktifitasnya (Soesilowati, 2008).

Demikian juga halnya dengan Kabupaten Sampang, permasalahan kemacetan lalu lintas juga terjadi di perkotaan Sampang. Lokasi stategis Kabupaten Sampang yang berada pada jalur 
lintas pergerakan dari arah Timur-Barat Pulau Madura (Satrio, 2014). Penduduk Kabupaten Pamekasan dan Kabupaten Sumenep yang menuju ke arah Surabaya atau sebaliknya, harus melintasi wilayah kabupaten Sampang. Sehingga sebagian besar pergerakan kendaraan tidak berkepentingan dengan Kabupaten Sampang. Oleh karena itu, terjadinya kemacetan tidak hanya disebabkan oleh lalu lintas lokal di kabupaten sampang, tetapi juga disebabkan kendaraan yang melintasi Kabupaten Sampang untuk tujuan dari dan ke Surabaya Pamekasan dan Kabupaten Sumenep (Satrio, 2014).

Lokasi di mana aktivitas dilakukan akan mempengaruhi manusia, barang dan jasa, yang akan mempengaruhi lokasi tempat aktivitas berlangsung (Huda, 2016). Dalam Kecamatan Sampang yang merubahan Ibukota Kabupaten Sampang memiliki beberapa titik yang mempengaruhi pergerakan. Pergerakan masuk ataupun keluar dari titik tersebut yang akhirnya menimbulkan kemacetan (Rosadi et al., 2018). Kemacetan yang terjadi menimbulkan penghambatan akan perkembangan Kecamatan sebagai Pusat Kegiatan Lokal (Anggraini \& Muta'ali, 2013).

Kemacetan yang terjadi di Kecamatan Sampang bersifat lokal dan terjadi di beberapa simpang ketika jam sibuk. Simpang Monumen Trunojoyo termasuk Simpang yang menimbulkan kemacetan. Kemacetan di Simpang Monumen Trunojoyo di sebabkan oleh karena simpang ini berada pada Jalur Jalan Nasional Surabaya-Sumenep yang di lewati kendaraat berat dan padat. Selain itu juga pada jam sibuk simpang ini merupakan penghubung pergerakan manusia dari pinggiran kota menuju tengah kota,

Dari permasalahan di atas, sehingga perlu dilakukan evaluasi kinerja jalan saat ini di Kecamatan Sampang untuk menghasilkan kualitas setiap ruas jalan dalam menerima beban volume jalan saat ini. Nanti hasil dari penelitian ini dapat digunakan sebagai rekomendasi peningkatan kualitas jalan di Kecamatan Sampang.

\section{METODOLOGI PENELITIAN}

Analisis kinerja simpang mengacu kepada panduan MKJI (Manual Kapasitas Jalan Indonesia, 1997). Untuk penerapan analisis di Simpang Monumen Trunojoyo menggunakan pendekatan simpang bersinyal dengan proses analisis sebagai berikut:

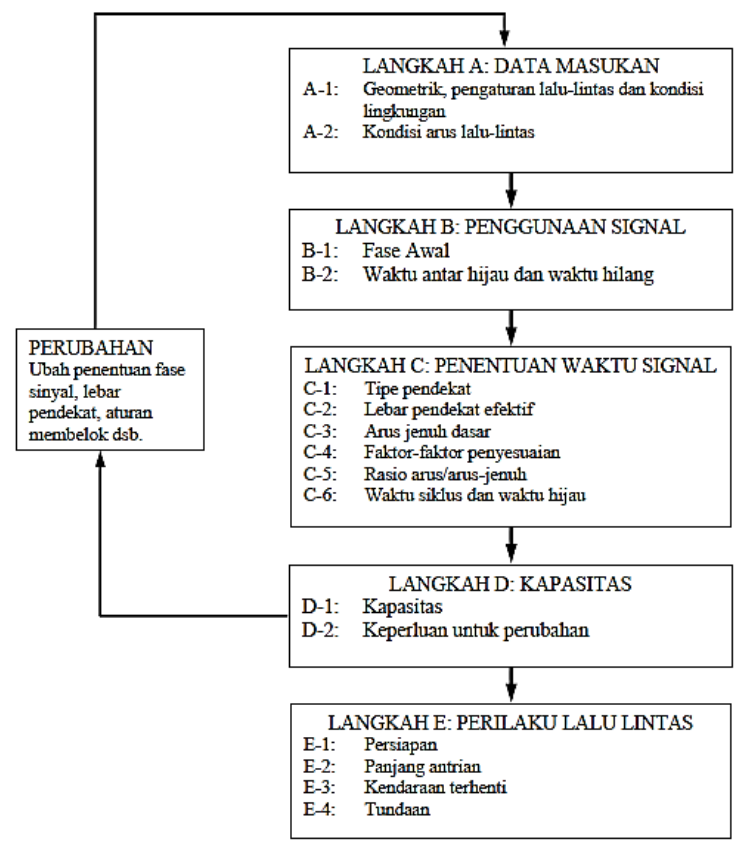

Gambar 1. Bagan Alir Analisa Simpang Bersinyal (MKJI, 1997, hal. 2 - 36) 

berikut.

Komponen analisis kinerja lalu lintas pada persimpangan jalan meliputi hal-hal sebagai

\section{Geometrik Persimpangan}

Geometrik persimpangan merupakan dimensi yang nyata dari suatu persimpangan. Oleh karenanya perlu di ketahui beberapa defenisi berikut ini:

- Approach (kaki persimpangan), yaitu daerah pada persimpangan yang digunakan untuk antrian kendaraan sebelum menyeberangi garis henti.

- Approach width $\left(\mathrm{W}_{\mathrm{A}}\right)$ yaitu lebar approach atau lebar kaki persimpangan

- Entry Width $\left(\mathrm{Q}_{\text {entry}}\right)$ yaitu lebar bagian jalan pada approach yang digunakan untuk memasuki persimpangan, diukur pada garis perhentian

- Exit width $\left(\mathrm{W}_{\text {exit }}\right)$ yaitu lebar bagian jalan pada approach yang digunakan kendaraan untuk keluar dari persimpangan

- Width Left Turn On Red (W belok kiri pada saat lampu merah

Kelima hal, Geometrik Persimpangan, tersebut diatas dapat dilihat dalam gambar sebagai berikut ini.

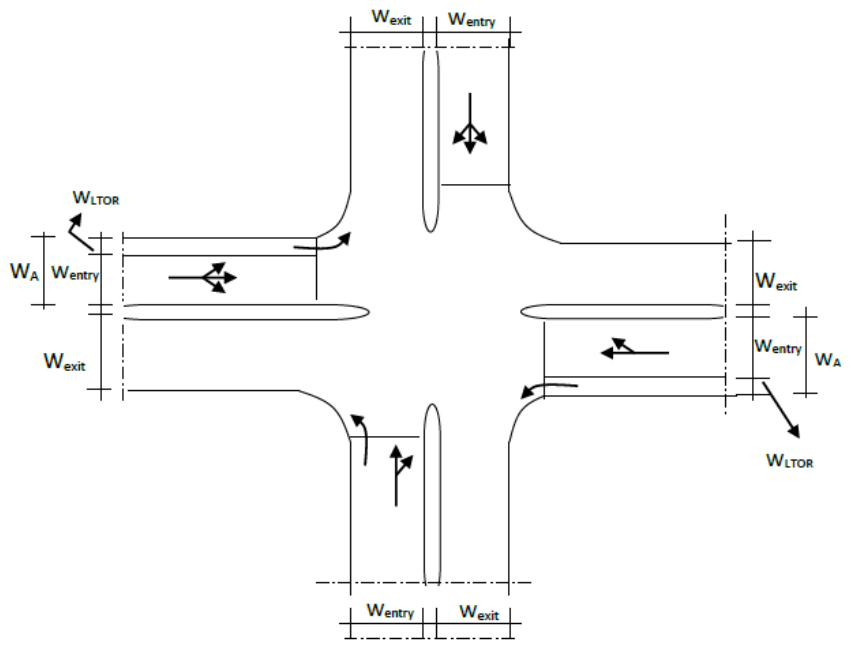

Gambar 2. Geometrik Persimpangan Dengan Lampu Lalu Lintas

\section{Kondisi Arus Lalu Lintas}

Arus lalu lintas (Q) pada setiap gerakan (belok kiri QLt, lurus QST, dan belok kanan QRT) dikonversi dari kendaraan per jam menjadi satuan mobil penumpang (smp) per jam dengan menggunakan ekivalen kendaraan penumpang (emp) untuk masing-masing pendekat terlindung dan terlawan. Nilai emp tiap jenis kendaraan berdasarkan pendekatnya dapat dilihat dalam tabel berikut ini:

Tabel 1. Nilai Emp Untuk Jenis Kendaraan Berdasarkan Pendekat

\begin{tabular}{ccc}
\hline \multirow{2}{*}{ Tipe kendaraan } & \multicolumn{2}{c}{ Emp } \\
\cline { 2 - 3 } & Pendekat terlindung & Pendekat terlawan \\
\hline LV & 1.0 & 1.0 \\
HV & 1.3 & 1.3 \\
MC & 0.2 & 0.4 \\
\hline
\end{tabular}

Sumber: MKJI (1997) 


\section{Karakteristik Sinyal dan Pergerakan Lalu Lintas}

Persimpangan pada umunya diatur oleh sinyal lalu lintas, hal ini dikarenakan beberapa alasan, seperti faktor keselamatan dan efektivitas pergerakan dari arus kendaraan dan pejalan kaki yang saling bertemu pada saat melintasi persimpangan. Parameter dasar dalam perhitungan pengaturan waktu sinyal secara umum meliputi parameter pergerakan, parameter waktu dan parameter ruang (geometrik). Dalam hal ini, perhitungan waktu sinyal juga termasuk perhitungan kinerja lalu lintas di persimpangan seperti tundaan, antrian, dan jumlah stop.

Penggunaan Sinyal diatur sebagai diuraikan dalam dua hal, Fase Sinyal dan Waktu Antar Hijau dan Waktu Hilang, dibawah ini.

- Fase Sinyal

Berangkatnya arus lintas selama waktu hijau sangat dipengaruhi oleh rencana fase yang memperhatikan gerakan kanan. Jika arus belok kanan dari suatu pendekat yang ditinjau dan/atau dari arah berlawanan terjadi dalam fase yang sama dengan arus berangkat lurus dan belok kiri dari pendekat tersebut maka arus berangkat tersebut dianggap terlawan.

Jika tidak ada arus belok kanan dari pendekat-pendekat tersebut atau jika arus belok kanan diberangkatkan ketika lalu lintas lurus dari arah berlawanan sedang menghadapi merah, maka arus berangkat tersebut dianggap sebagai arus terlindung.

- Waktu Antar Hijau Dan Waktu Hilang

Waktu antar hijau didefenisikan sebagai waktu antara hijau suatu fase dan awal waktu hijau fase berikutnya. Waktu antar hijau terdiri dari waktu kuning dan waktu merah semua. Waktu merah semua yang diperlukan untuk pengosongan pada akhir setiap fase, harus memberi kesempatan bagi kendaraan terakhir (melewati garis henti pada akhir sinyal kuning) berangkat dari titik konflik sebelum kedatangan kendaraan pertama pada fase berikutnya.

Waktu Merah Semua dirumuskan sebagai berikut :

$$
M E R A H S E M U A=\left[\frac{\left(L_{E V}+l_{E V}\right.}{V_{L V}}-\frac{L_{A V}}{V_{A V}}\right]_{\max }
$$

Dimana :

$$
\begin{aligned}
\mathrm{LEV}_{\mathrm{EV}} \mathrm{L}_{\mathrm{AV}}= & \text { jarak dari garis henti ke titik konflik masing-masing untuk kendaraan } \\
& \text { yang berangkat dan yang datang }(\mathrm{m}) \\
= & \text { panjang kendaraan yang berangkat }(\mathrm{m}) \\
\mathrm{l}_{\mathrm{EV}} & \begin{array}{l}
\text { kecepatan masing-masing kendaraan yang berangkat dan yang datang } \\
\mathrm{V}_{\mathrm{EV}}, \mathrm{V}_{\mathrm{AV}}=
\end{array}
\end{aligned}
$$

Nilai-nilai yang dipilih untuk $\mathrm{V}_{\mathrm{EV}}, \mathrm{V}_{\mathrm{AV}}$ dan $\mathrm{l}_{\mathrm{EV}}$ tergantung dari komposisi lalu lintas dan kondisi kecepatan pada lokasi. Untuk Indonesia, nilai-nilai tersebut ditentukan sebagai berikut :

$$
\begin{array}{lc}
\text { Kecepatan kendaraan yang datang: } & \mathrm{V}_{\mathrm{AV}}=10 \mathrm{~m} / \mathrm{det} \text { (kend. bermotor) } \\
\text { Kecepatan kendaraan yang berangkat: } & \mathrm{V}_{\mathrm{EV}}=10 \mathrm{~m} / \mathrm{det} \text { (kend. bermotor) } \\
& 3 \mathrm{~m} / \mathrm{det} \text { (kend tak bermotor) } \\
& 1.2 \mathrm{~m} / \mathrm{det} \text { (pejalan kaki) } \\
& \\
\text { Panjang kendaraan yang berangkat: } & \mathrm{l}_{\mathrm{EV}}=5 \mathrm{~m}(\mathrm{LV} \text { atau HV) } \\
& 2 \mathrm{~m}(\mathrm{MC} \text { atau } \mathrm{UM})
\end{array}
$$

Jika periode merah semua untuk masing-masing akhir fase telah ditetapkan maka waktu hilang (LTI) untuk simpang dapat dihitung sebagai jumlah dari waktu-waktu antar hijau.

$$
L T I=\sum(\text { Merah semua }+ \text { Kuning }) i=\sum I_{g i}
$$




\section{HASIL DAN PEMBAHASAN}

Profil dasar simpang Monumen Trunojoyo berupa simpang bersinyal yang mempunyai 4 jumlah pendekat dengan kondisi lingkungan komersial seperti terlihat pada Gambar 3 dengan geometri sebagai berikut :

Ruas jalan :

- N: J1 Pahlawan (4/2D); C0= 1650 per lajur; $F C s p=1 ; F C w=1.09 ; F C s f=0.97 ; F C c s=0.86$

- W: Jl Bahagia (4/2D); $\mathrm{C} 0=1650$ per lajur; $\mathrm{FCw}=1.09 ; \mathrm{FCsp}=1 ; \mathrm{FCsf}=0.95 ; \mathrm{FCcs}=0.86$

- E: J1 Bahagia (2/2UD); $\mathrm{C} 0=2900$ total 2 arah; $\mathrm{FCw}=1.00 ; \mathrm{FCsp}=1$; FCsf=0.89; FCcs= 0.86

- S: J1 Trunojoyo (4/2UD); $\mathrm{C} 0=1500$ per lajur; $\mathrm{FCsp}=1 ; \mathrm{FCw}=1.09$; $\mathrm{FCsf}=0.97$; $\mathrm{FCcs}=$ 0.86

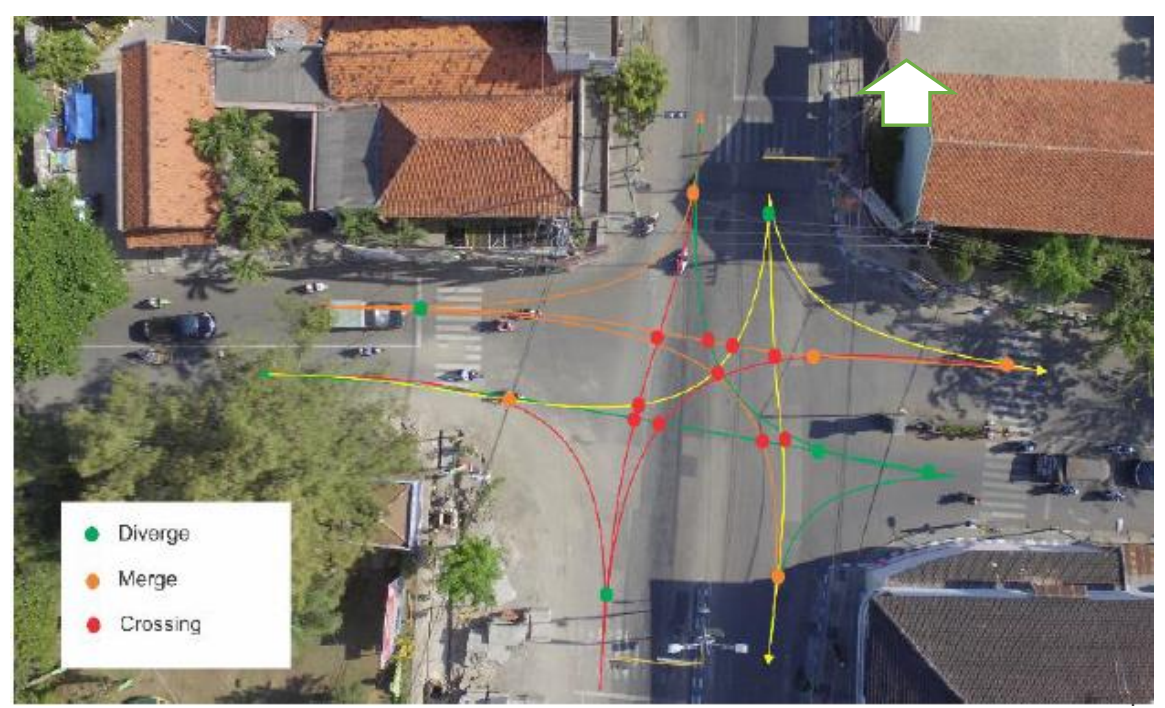

Gambar 3. Diskripsi Simpang Monumen Trunojoyo

Analisis simpang sesuai panduan MKJI, 1997 dijelaskan sebagai berikut.

a. Data kondisi sinyal (fase)

Dengan mengetahui dari hasil survei di lapangan maka dapat ditentukan waktu siklus Pada simpang Monumen, terdapat empat fase lalu lintas. Lama waktu pengoperasian sinyal lalu lintas seperti terlihat pada Tabel 2 .

Tabel 2. Model Tiga Titik Pengamatan

\begin{tabular}{lllcccc}
\hline Sinyal & Lengan & Tipe pendekat & \multicolumn{4}{c}{ Waktu (detik) } \\
\cline { 3 - 6 } & & & Merah & Hijau & Kuning & Merah semua \\
\hline Fase 1 & Utara & Terlindung (P) & 48 & 20 & 3 & 1.5 \\
Fase 2 & Timur & Terlindung (P) & 58 & 10 & 3 & 0.3 \\
Fase 3 & Barat & Terlindung (P) & 53 & 15 & 3 & 1.6 \\
Fase 4 & Selatan & Terlindung (P) & 48 & 20 & 3 & 0.9 \\
\hline \multicolumn{3}{c}{ Waktu Siklus } \\
\hline
\end{tabular}

Dari tabel diatas, diketahu bahwa karakteristik simpang monumen adalah memiliki siklus waktuyang cukup lama yaitu 81.3 detik untuk menuntaskan satu kali siklus sinyalnya. 
b. Kondisi arus lalu lintas dan data arus lalu lintas

Karakteristik arus lalu lintas di simpang monumen dapat dilihat pada gambar diatas, dimana arus paling besar berasal dari sisi utara dan selatan yaitu arus lalu lintas Surabaya-Sumenep.

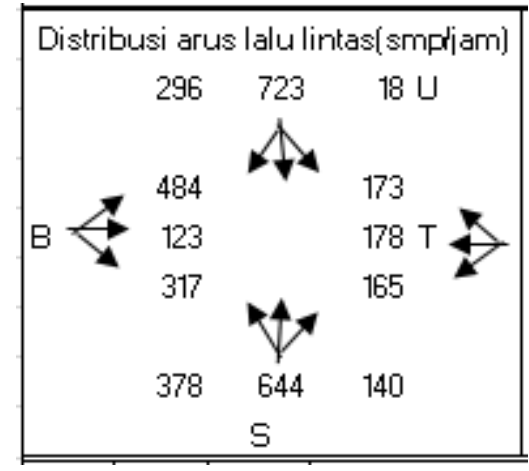

Gambar 4. Distribusi Arus Lalu Lintas di Setiap Pendekat pada Simpang Monumen (Sumber: Hasil Analisis)

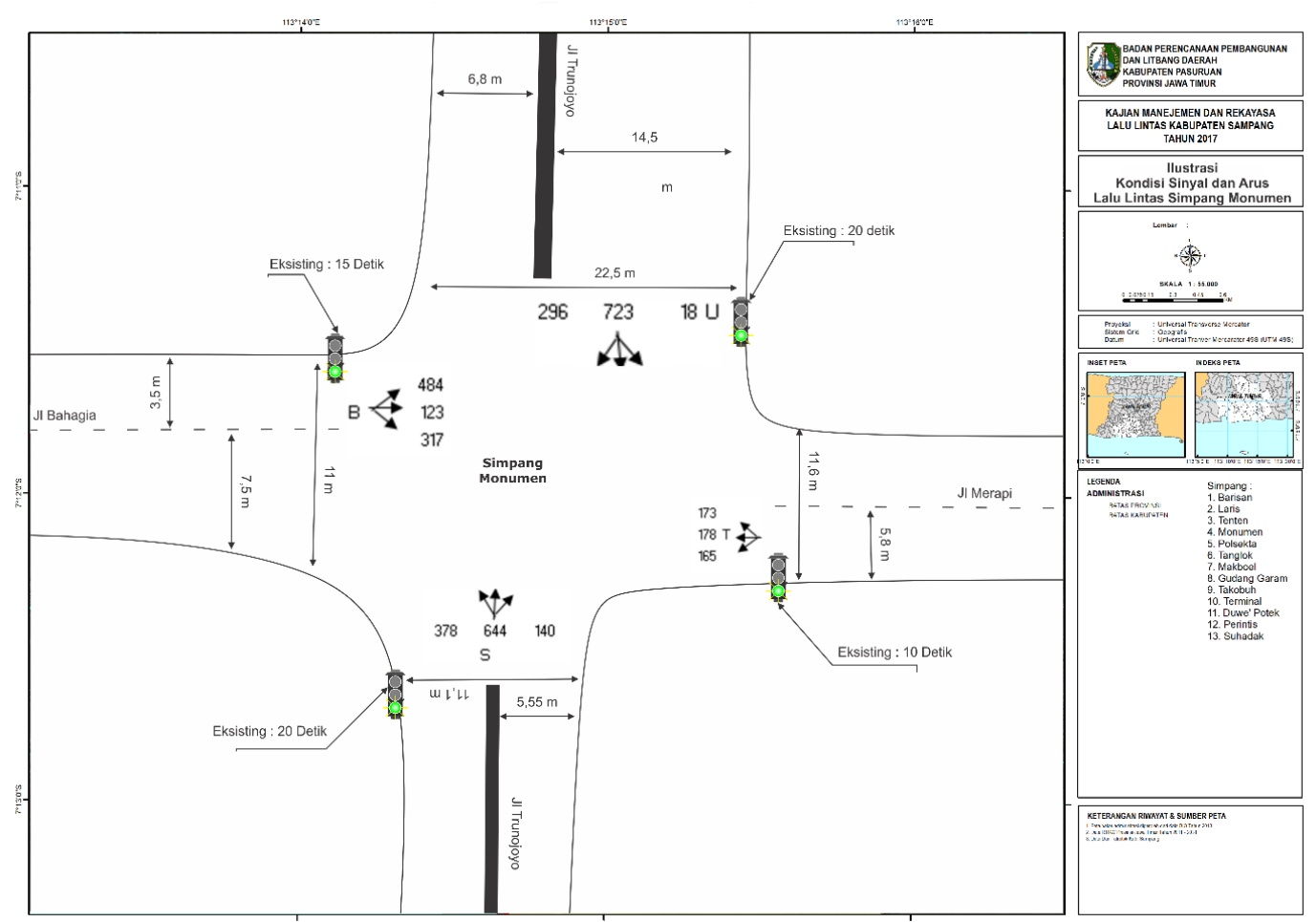

Gambar 5. Ilustrasi Kondisi Sinyal dan Arus Lalu Lintas Simpang Monumen (Sumber: Hasil Analisis)

c. Arus jenuh

Arus jenuh (S) dihitung sesuai panduan MKJI, 1997, sebagaimana pada tabel sebagai berikut. 
Tabel 2. Perhitungan arus jenuh Simpang Monumen

\begin{tabular}{lcccccccc}
\hline Pendekat & \multicolumn{9}{c}{$S=S_{0} * F_{C S} * F_{S F} * F_{G} * F_{P} * F_{R T} * F_{L T}$} & & $\mathrm{~S}$ \\
\cline { 2 - 9 } & $S_{0}=600 * W_{e}$ & $F_{C S}$ & $F_{S F}$ & $F_{G}$ & $F_{P}$ & $F_{R T}$ & $F_{L T}$ & \\
\hline UTARA & 4080 & 1.00 & 0.880 & 1.0 & 1.00 & 1.07 & 1.00 & 3842 \\
SELATAN & 3900 & 1.00 & 0.820 & 1.0 & 1.00 & 1.02 & 0.96 & 3145 \\
TIMUR & 3300 & 1.00 & 0.840 & 1.0 & 1.00 & 1.07 & 0.96 & 2840 \\
BARAT & 3300 & 1.00 & 0.880 & 1.0 & 1.00 & 1.06 & 0.94 & 2905 \\
\hline
\end{tabular}

Sumber: Hasil Analisis

d. Kapasitas dan tingkat pelayanan atau degree of saturation (DS) Arus lalu lintas $(\mathrm{Q})$ pada keadaan terlindung dihitung pada gerakan lurus dan belok kanan. Rasio arus atau FR (Q/S) adalah perbandingan arus dan arus jenuh.

Tabel 4. Perhitungan tingkat pelayanan Simpang Monumen

\begin{tabular}{lrrr}
\hline Pendekat & \multicolumn{1}{c}{$Q$} & $C=S * g / c$ & $D S=Q / C$ \\
\hline UTARA & 1037 & 980 & 1.0581 \\
SELATAN & 1163 & 1099 & 1.0582 \\
TIMUR & 515 & 487 & 1.0575 \\
BARAT & 923 & 873 & 1.0573 \\
\hline
\end{tabular}

Hasil perhitungan menunjukkan bahwa semua pendekat memiliki nilai derajat kejenuhan DS > 0.75. Ini berarti bahwa simpang tersebut mendekati lewat-jenuh, yang akan mcnyebabkan antrian panjang pada kondisi lalulintas puncak. Maka jalan tersebut harus diatur ulang untuk waktu sinyal maupun kondisi jalannya. Berdasrkan MKJI 1997 kemungkinan untuk menanmbah kapasitas simpang melalui salah satu dari tindakan sebagai berikut: (1) Penambahan lebar pendekat, (2) Perubahan Fase Sinyal, dan (3) Pelarangan Gerakan(-gerakan) belok-kanan.

Untuk alternatif peningkatan kinerja simpang, dilakukan simulasi solver dengan tujuan memperoleh optimasi pengaturan sinyal dan geometrik simpang yang berdampak pada perbaikan kinerja simpang atau nilai DS simpang.

Simulasi solver dilakukan dengan merubah waktu hijau dan lebar efektif setiap pendekat untuk memperoleh kinerja simpang pada angka DS yang diharapkan. Dalam simulasi ini akan ditetapkan nilai DS $\leq 0.75$, yaitu pada level 0.70. Ilustrasi simulasi solver menggunakan Microsoft excel digambarkan sebagai berikut Gambar 4. Pada simulasi solver, diperlukan nilai target yang dikehendaki (dalam hal ini nilai DS), berdasarkan nilai yang dapat diubah dalam hal ini nilai waktu hijau, lebar efektif tiap pendekat, dan menentukan constraints ataupun batasan-batasan pada nilai waktu hilang total, waktu siklus yang disesuaikan, waktu hijau minimum dan maksimum, lebar efektif minimum dan maksimum, serta tidak ada nilai negative. 


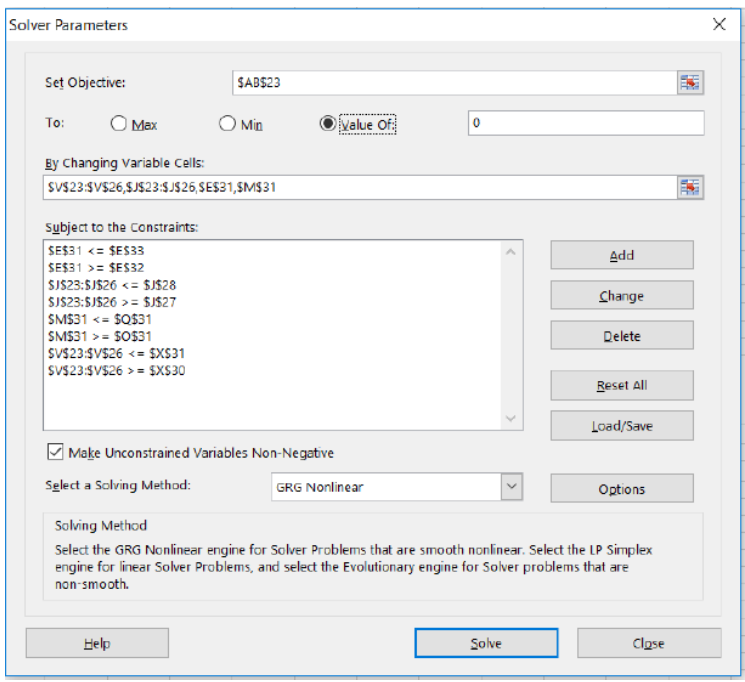

Gambar 6. Tampilan simulasi solver dengan penetapan nilai target, nilai yang diubah, serta nilai constraints

\begin{tabular}{|c|c|}
\hline Solver Results & \\
\hline $\begin{array}{l}\text { Solver found a solution. All Constraints and optimality } \\
\text { conditions are satisfied. }\end{array}$ & Reports \\
\hline Keep Solver Solution & $\begin{array}{l}\text { Answer } \\
\text { Sensitivity } \\
\text { Limits }\end{array}$ \\
\hline$\square$ Return to Solver Parameters Dialog & $\square$ Outline Reports \\
\hline Cancel & Save Scenario... \\
\hline \multicolumn{2}{|c|}{$\begin{array}{l}\text { Solver found a solution. All Constraints and optimality conditions are } \\
\text { satisfied. }\end{array}$} \\
\hline $\begin{array}{l}\text { When the GRG engine is used, Solver has found at least a I } \\
\text { When Simplex LP is used, this means Solver has found a glc }\end{array}$ & $\begin{array}{l}\text { cal optimal solution. } \\
\text { bal optimal solution. }\end{array}$ \\
\hline
\end{tabular}

Gambar 7. Tampilan simulasi solver dengan penginformasian keberhasilan simulasi solver dengan optimasi nilai-nilai yang diubah untuk mencapai target nilai DS yang ditetapkan

Tabel 5. Hasil optimasi solver Simpang Monumen

\begin{tabular}{lllll}
\hline Pendekat & $\begin{array}{c}\text { Nilai g } \\
\text { optimum } \\
\text { (detik) }\end{array}$ & $\begin{array}{c}\text { Nilai We } \\
\text { optimum } \\
\text { (meter) }\end{array}$ & $\begin{array}{c}\text { Nilai DS } \\
\text { saat ini }\end{array}$ & $\begin{array}{c}\text { DS Setelah } \\
\text { optimasi }\end{array}$ \\
\hline UTARA & 30 & 7.14 & 1.0581 & 0.6848 \\
SELATAN & 30 & 9.65 & 1.0582 & 0.6638 \\
TIMUR & 21 & 5.63 & 1.0575 & 0.6846 \\
BARAT & 30 & 6.66 & 1.0573 & 0.7000 \\
\hline
\end{tabular}

Berdasarkan simulasi, diperoleh nilai waktu hijau yang optimum untuk pendekat Utara 30 detik, Selatan 30 detik, Timur 21 detik dan Barat 30 detik, serta nilai lebar efektif lajur yang optimum yaitu 7,14 meter, untuk pendekat Utara, 9.65 meter, untuk pendekat Selatan, 5.63 meter, untuk pendekat Timur dan 6.66 meter, untuk pendekat Barat. Nilai DS di seluruh pendekat dengan demikian akan memenuhi sesuai yang dipersyaratkan MKJI 1997, yaitu berkisar antara 0.66 hingga $0.7<0.75$. 


\section{KESIMPULAN}

Berdasarkan pembahasan diatas diketahui bahwa kinerja Simpang Monumen di Kecamatan Sampang dibawah standar dengan nilai DS pada semua pendekat $>0.75$. Simulasi solver dilakukan untuk meningkatkan kinerja simpang dengan merubah siklus pada persinyalan, terutama memodifikasi waktu hijau (detik) dan memodifikasi lebar efektif setiap pendekat. Didapatkan hasil optimasi nilai DS berkisar antara 0.66 hingga $0.7<0.75$.

\section{DAFTAR PUSTAKA}

Anggraini, R. A., \& Muta'ali, L. (2013). "Pola Hubungan Pertumbuhan Ekonomi dan Pembangunan Manusia di Provinsi Jawa Timur Tahun 2007-2011". Jurnal Bumi Indonesia, Vol. 2, No. 3, Agustus 2013, Hal. : 233-242.

Halim, H., Mustari, I. \& Zakariah, A. (2019). “Analisis Kinerja Ruas Jalan Satu Arah dengan Menggunakan Mikrosimulasi VISSIM (Studi Kasus: Jalan Masjid Raya di Kota Makassar)". Jurnal Manajemen Aset Infrastrukutr \& Fasilitas, Vol. 3, No. 2, September 2019. Hal. : 99-108.

Huda, M. (2016). "Pemodelan Trip Attraction Kendaraan Pribadi pada Rumah Makan (Studi Kasus: Jl. Mulyosari Surabaya)". Jurnal Agregat, Vol. 1, No. 1, November 2016. Hal. : 33-38.

MKJI (1997). Manual Kapasitas Jalan Indonesia 1997. Bina Karya \& Sweeroad. Direktorat Bina Jalan Kota. Direktorat Jendral Bina Marga. Jakarta.

Rosadi, S., Abidin, Z., \& Huda, M. (2018). "Analisis Kinerja Lalu Lintas Akibat Pembangunan Pelabuhan Taddan di Kabupaten Sampang”. Jurnal Agregat, Vol. 3, No. 2. November 2018. Hal. : 243-251.

Satrio, G., Arifin, M. Z., \& Wicaksono A. (2014). "Kajian Potensi Penumpang Kereta Api Lintas Madura (Bangkalan-Sumenep Pp) Dengan Menggunakan Metode Stated Preference". Jurnal Mahasiswa Jurusan Teknik Sipil, Vol. 1, No. 2, 2014,

Soesilowati, E. (2008). Dampak Pertumbuhan Ekonomi Kota Semarang Terhadap Kemacetan Lalulintas Di Wilayah Pinggiran dan Kebijakan Yang Ditempuhnya. Jurnal Ekonomi dan Kebijakan, Vol. 1, No. 1. September 2008, Hal. : 9-18.

Suprayitno, H. \& Soemitro, R.A.A. (2018). "Preliminary Reflexion on Basic Principle of Infrastructure Asset Management". Jurnal Manajemen Aset Infrastruktur \& Fasilitas, Vol. 2, No.1, Maret 2018.

Wibisono, R.E. \& Cahyono, M.S.D. (2018). "Kinerja Lalu Lintas Simpang di Kalen-Majenang Akibat Pembangunan Saluran Irigasi Waduk Kalen di Kecamatan Kedungpring Kabupaten Lamongan”. Jurnal Manajemen Aset Infrastruktur \& Fasilitas, Vol. 2, No. 2, September 2018. 


\section{(e)ISSN 2615-1847 (p)ISSN 2615-1839}

Jurnal Manajemen Aset Infrastruktur \& Fasilitas - Vol. 4, No. 4, Oktober 2020 